\title{
Diminished finger volume pulse in borderline hypertension: Evidence for early structural vascular abnormality
}

\begin{abstract}
Digital volume pulse during maximum dilation was determined in 27 patients with borderline essential hypertension (BHT) and 28 age-matched normotensive controls (NT). Finger pulse volume (PV) and finger systolic pressure (SBP) were measured by pneumoplethysmography during vasodilation induced by combining direct and reflex heat dilation and reactive hyperemia. Finger SBP was higher $(p<0.01)$ in BHT than in NT $(120 \pm 18.7$ vs. $104 \pm 14.8 \mathrm{~mm} \mathrm{Hg}$, respectively); PV was lower $(p<0.01)$ in BHT than in NT $(9.7 \pm 4.2$ vs. $15.3 \pm 6 \mathrm{ml} / 5 \mathrm{ml}$ finger $\left.\times 10^{-3}\right)$. Pulse volume correlated inversely with SBP in BHT $(r=-0.40, p<0.05)$ but was unrelated to SBP in NT. Pulse volume was not altered by high or low sodium intake in BHT or NT despite significant changes in plasma renin activity (PRA). In BHT finger vessels are less distensible at a higher pressure than in NT. This abnormality is demonstrable during maneuvers to withdraw sympathetic tone and is not influenced by alteration of PRA. These data support the concept that BHT can produce structural vascular change, and demonstrate that this abnormality can be detected by a relatively simple method. (AM HEART $J$ 104:812, 1982.)
\end{abstract}

Andrew J. Zweifler, M.D., and M. Gary Nicholls, M.B.Ch.B. Ann Arbor, Mich.

The need for an aggressive therapeutic approach to all patients with mild hypertension remains uncertain. Recent controlled trials ${ }^{1,2}$ suggest that, in general, lowering the blood pressure of patients with diastolic blood pressure over 90 to $95 \mathrm{~mm} \mathrm{Hg}$ reduces the death rate; however, the results were not conclusive for women or for men under 50 years of age. The decision to treat, particularly in patients with borderline hypertension and those with diastolic blood pressure 90 to $95 \mathrm{~mm} \mathrm{Hg}$, is still a difficult one. Evidence of cardiovascular damage such as left ventricular hypertrophy or nephrosclerosis would clearly justify therapeutic intervention, but techniques for detecting these cardiac and renal abnormalities are relatively crude. A more sensitive indicator of early vascular damage from hypertension would be of value. We report evidence that indicates that measurement of the digital volume pulse during maximum dilation is a method for detecting vascular change in patients with borderline hypertension.

From the Department of Internal Medicine, Division of Hypertension, University of Michigan Medical School.

Received for publication April 6, 1981; revision received May 18, 1981; accepted June 2, 1981.

Reprint requests: Andrew J. Zweifler, M.D., Division of Hypertension, Box 48, R6669 Kresge Medical Research Building, University of Michigan Medical School, Ann Arbor, MI 48109.

\section{METHODS}

Study population. Twenty-seven patients, 19 men and 8 women, mean age $31.9 \pm$ SD 9.4 years, with borderline essential hypertension (BHT) were studied. All patients had had at least one blood pressure reading over $150 \mathrm{~mm}$ $\mathrm{Hg}$ systolic or $90 \mathrm{~mm} \mathrm{Hg}$ diastolic, or both, and on another occasion a blood pressure of less than $150 \mathrm{~mm} \mathrm{Hg}$ systolic or $90 \mathrm{~mm} \mathrm{Hg}$ diastolic, or both, in the previous month. No patient had a serum creatinine concentration greater than $1.5 \mathrm{mg} \%$ or evidence of left ventricular hypertrophy on ECG. None had received antihypertensive medication in the preceding 4 weeks. Twenty-eight healthy normotensive volunteers (NT) (15 men and 13 women; mean age $31.9 \pm \mathrm{SD} 8.8$ years) were studied also. These studies were approved by the University of Michigan Medical School Committee to Review Grants for Clinical Research and Investigation Involving Human Beings. All persons read and signed an informed consent form describing the test to be done.

Plethysmography. The digital plethysmograph consisted of a translucent plastic cylinder, sealed at the distal end with a rubber stopper penetrated by a large-caliber steel needle attached to a three-way stopcock, and fixed with a malleable plastic material forming an airtight seal to the skin at a point midway between the proximal and distal interphalangeal joints of the third finger of the hand. The chamber was connected by stiff tubing from the stopcock to a Statham pressure transducer. Output from the transducer was recorded on a Gilson polygraph. The system was calibrated directly by the introduction of 0.015 ml air through the stopcock. An inflatable cuff with a 

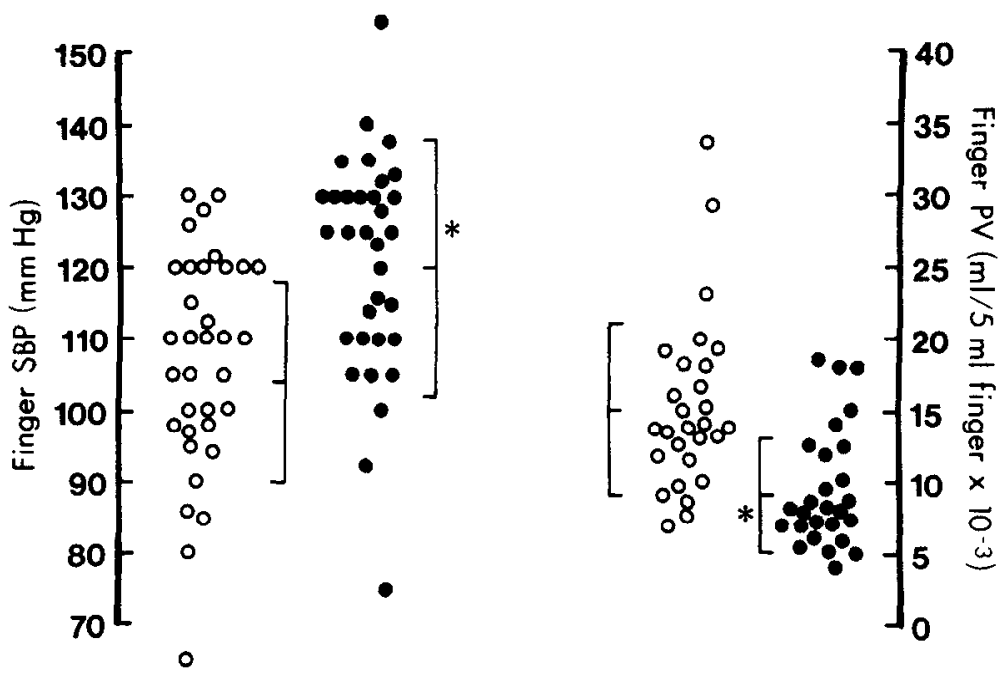

Fig. 1. Finger systolic blood pressure $(S B P)$ and finger pulse volume $(P V)$ in normal subjects (open circles) and in patients with borderline hypertension (closed circles). Brackets indicate \pm standard deviation around the mean. ${ }^{*} p<0.01$, hypertensive patients vs. normal subjects.

Table I. Brachial and finger blood pressure and finger pulse volume during maximum vasodilation in patients with borderline hypertension and in normal subjects

\begin{tabular}{lccccc}
\hline & \multicolumn{3}{c}{ Brachial } & & \multicolumn{2}{c}{ Finger } \\
\cline { 2 - 3 } \cline { 5 - 6 } & $\begin{array}{c}\text { Systolic } \\
(\mathrm{mm} \mathrm{Hg})\end{array}$ & $\begin{array}{c}\text { Diastolic } \\
(\mathrm{mm} \mathrm{Hg})\end{array}$ & & $\begin{array}{c}\text { Systolic } \\
(\mathrm{mm} \mathrm{Hg})\end{array}$ & $\begin{array}{c}\text { Pulse volume } \\
\left(\mathrm{ml} / 5 \mathrm{ml} \mathrm{finger} \times 10^{-3}\right)\end{array}$ \\
\hline Normal subjects & $112 \pm 10.6$ & $69 \pm 6.5$ & & $104 \pm 14.8$ & $15.3 \pm 6.0$ \\
Patients with BHT & $132 \pm 11.3^{*}$ & $84 \pm 7.9^{*}$ & & $120 \pm 18.7^{*}$ & $9.7 \pm 4.2^{*}$ \\
\hline
\end{tabular}

Values expressed as mean \pm standard deviation.

${ }^{*}$ Hypertensive patients vs. normal subjects; $p<0.01$.

bladder $24 \mathrm{~mm}$ wide was fastened firmly around the proximal phalanx for the measurement of finger systolic pressure and for inducing ischemia of the finger. Persons were studied in recumbency with the arm slightly elevated on foam rubber cushions.

Digital pulse volume and finger systolic pressure techniques. The amplitude of the digital volume pulse and the systolic blood pressure in the finger were measured under conditions designed to produce maximal dilation. ${ }^{3}$ The room temperature was $80^{\circ} \mathrm{F}$, and readings were obtained only after (1) the individual's body was heated with the aid of blankets and electric pads until oral temperature increased at least $0.5^{\circ} \mathrm{F} ;(2)$ the hand had been warmed directly with a heating pad for 10 minutes; and (3) the finger had been subjected to ischemia for 5 minutes. Finger systolic pressure was determined by inflating the finger cuff to $30 \mathrm{~mm} \mathrm{Hg}$ above brachial systolic pressure (previously determined by auscultation) and then deflating steadily while monitoring the cuff pressure and noting the pressure at which digital pulsations returned. Pulse volume was calculated based on a "pulse deflection" obtained by averaging 10 consecutive pulse-height measurements and was expressed per $5 \mathrm{ml}$ finger volume utilizing the formula of pulse volume $(\mathrm{ml} / 5$ $\mathrm{ml}$ finger $)=[($ pulse deflection $)(0.015 /$ calibration deflection) $] /[($ finger volume/5)]. The coefficients of variation for these measurements determined in seven normal subjects on 3 separate days were $16.7 \%$ for pulse volume and $9.2 \%$ for finger systolic pressure.

Study protocol. Pulse volume (PV) and finger systolic pressure (SBP) during maximum dilation were determined in all individuals. In addition, these measurements were obtained in six patients with BHT and in six normal subjects after 4-day periods of high salt ( $250 \mathrm{mEq}$ sodium/ day) and low salt intake (20 mEq sodium/day). Supine plasma renin activity (PRA) ${ }^{4}$ and 24-hour urinary sodium excretion were also measured in these individuals.

\section{RESULTS}

Digital PV and finger SBP. Brachial blood pressure by auscultation was $20 / 15 \mathrm{~mm} \mathrm{Hg}$ higher in patients with BHT than in normal subjects (Table I). Similarly, systolic blood pressure in the finger was higher (120 mm Hg) in BHT than in NT (104 mm Hg). Maximum amplitude of the digital volume pulse, however, was smaller $\left(9.7 \mathrm{ml} / 5 \mathrm{ml}\right.$ finger $\left.\times 10^{-3}\right)$ in BHT than in NT $\left(15.3 \mathrm{ml} / 5 \mathrm{ml}\right.$ finger $\left.\times 10^{-3}\right)$. More 
Table II. Finger systolic blood pressure and pulse volume, plasma renin activity, and urinary sodium excretion during low salt and high salt diet in patients with borderline hypertension and in normal subjects

\begin{tabular}{llcccc}
\hline & Diet & $\begin{array}{c}\text { Systolic } \\
(\mathrm{mm} \mathrm{Hg})\end{array}$ & $\begin{array}{c}\text { Pulse volume } \\
(\mathrm{ml})^{*}\end{array}$ & $\begin{array}{c}\text { Sodium excretion } \\
(\mathrm{mEq} / 24 \mathrm{hr})\end{array}$ & $\begin{array}{c}\text { Supine PRA } \\
(\mathrm{ng} / \mathrm{ml} / \mathrm{hr})\end{array}$ \\
\hline Normal subjects & Low salt & 110 & 11.6 & 58 & 2.5 \\
$(\mathrm{n}=6)$ & High salt & 112 & 11.5 & $212 \dagger$ & $0.58 \ddagger$ \\
Patients with BHT & Low salt & 118 & 8.3 & 15 & 3.1 \\
$(\mathrm{n}=6)$ & High salt & 128 & 8.7 & $194 \dagger$ & $0.48 \dagger$ \\
\hline
\end{tabular}

${ }^{*} \mathrm{ml} / 5 \mathrm{ml}$ finger $\times 10^{-3}$.

$t p<0.05$.

$\ddagger p<0.01$, high salt vs. low salt.

than $80 \%$ of normal subjects had PV greater than 10 $\mathrm{ml} / 5 \mathrm{ml}$ finger $\times 10-3$, whereas $75 \%$ of the hypertensives had PV less than $10 \mathrm{ml} / 5$ finger $\times 10^{-3}$, and approximately $15 \%$ of the patients with BHT fell below the normal range (Fig. 1 ).

Digital PV related to finger SBP. The relationship of PV to SBP in the finger was determined by calculating linear correlation coefficients for these two variables in both BHT and NT. Pulse volume correlated inversely with SBP in hypertensives $(r=-0.40$, $p<0.05$ ), while it was unrelated to SBP in normals $(r=-0.01)$.

Influence of dietary sodlum intake. Restriction of sodium intake with associated increase in PRA was not accompanied by any change in PV in normal subjects or in hypertensives (Table II). Finger blood pressure was not influenced significantly by dietary sodium intake in NT or BHT.

\section{DISCUSSION}

Reduced digital PV in borderline hypertension. These data document a reduction in the volume pulse in the finger of patients with BHT compared with age-matched normotensives. This pulse reflects volume changes in venules and capillaries primarily ${ }^{5}$; it represents the time course of the differences between volume of inflow and volume of outflow in the digit. ${ }^{6}$ Three major determinants of the volume pulse are flow velocity, wave velocity, and tissue elasticity. ${ }^{7}$ A diminished pulse volume could result from a reduction in flow velocity, a reduction of perivascular or vascular compliance, or an increase in wave velocity. Digital blood flow has been found to be normal in most hypertensives ${ }^{8,9}$ despite elevated inflow pressure, so it is unlikely that alteration of flow rate can explain the small volume pulses noted in our patients.

Decreased vascular compllance in hypertension. There is ample evidence, however, for the existence of structural change in peripheral arteries in established hypertension ${ }^{10,11}$ and in BHT. ${ }^{12,13}$ In addition, there is evidence of structural change in peripheral veins in hypertension. ${ }^{14,16}$ Nakayama and Azuma ${ }^{16}$ were able to calculate vascular compliance in the finger, utilizing the quantitative relationship between digital blood pressure and the volume pulse, and found it to be reduced in hypertensives. It seems most likely, then, that the abnormality of the digital volume pulse we have noted is related to structural changes in the vessels of the finger caused by hypertension. The fact that there is a significant inverse relationship between pulse volume and systolic blood pressure in our borderline hypertensive patients but not in normal subjects is consistent with this hypothesis. We have not studied patients with established hypertension, but demonstration of persistence of the inverse relationship between systolic blood pressure and pulse volume at higher pressures would strengthen the concept that the reduced pulse volume in BHT results from structural alterations in the vasculature. Finally, it is possible that an alteration in pulse wave velocity could contribute to the reduced digital pulse volume in BHT, because pulse wave velocity has been found to be increased in patients with established hypertension $^{17}$; however, pulse wave velocity in BHT has not been measured by us or by others.

Structural vaecular change in hypertenelon. Although it is possible that the reduction in amplitude of the volume pulse we observed in BHT is caused by increased neurogenic vascular tone with diminished blood flow rather than by structural changes, this seems unlikely. Our patients were studied under conditions demonstrated by others to eliminate nervous control of cutaneous vessels ${ }^{18}$ and to produce maximum vasodilation in vessels of the upper extremity. ${ }^{10,11,19}$ Although acute injection of vasoactive agents such as angiotensin II will not constrict vessels maximally dilated by heat and reactive hyperemia, ${ }^{10}$ we were interested to observe the effect of manipulation of sodium intake with associated longer term changes in the renin-angio- 
tensin system on the finger pulse volume measured during maximum dilation. Despite significant changes in plasma renin activity, no change in the volume pulse was observed. It does not appear likely, then, that angiotensin, or for that matter other humoral factors, causes the reduced finger pulse volume observed under the conditions of our study.

Clinical significance. The presence of a diminished volume pulse in the finger in some patients with BHT is of potential practical significance, particularly inasmuch as the method of measurement is relatively simple. If this hemodynamic abnormality does reflect structural vascular change, its detection could be of value in the clinical assessment of patients with borderline blood pressure elevation. Presence of this abnormality might be an early sign of cardiovascular injury in such patients. As such it could be an additional factor in therapeutic decision making in BHT.

We acknowledge the assistance of Miguel West, Janet Layne, and Jenny Hackforth-Jones for plethysmography and Paula Beitler for data analysis.

\section{REFERENCES}

1. Hypertension Detection and Follow-up Program Cooperative Group: Five-year findings of the hypertension detection and follow-up program. I. Reduction in mortality of persons with high blood pressure, including mild hypertension. JAMA 242:2562, 1979

2. Australian National Blood Pressure Study Management Committee: The Australian therapeutic trial in mild hypertension. Lancet 1:1261, 1980.

3. Zweifler AJ, Cushing G, Conway J: The relationship between pulse volume and blood flow in the finger. Angiology 18:591, 1967.

4. Haber E, Koerner T, Page LB, Kliman B, Purnode A: Application of a radioimmunoassay for angiotensin $I$ to the physiologic measurement of plasma renin activity in normal healthy subjects. J Clin Endocrinol Metab 29:1349, 1969.

5. Gaskell P, Burton A: Local postural vasomotor reflexes arising from the limb veins. Circ Res 1:27, 1953.

6. Burch GE: Method for recording simultaneously the time course of digital rate and of digital volume of inflow, outflow and the difference between inflow and outflow during a single pulse cycle in man. J Appl Physiol 7:99, 1954.

7. Nakayama R, Kobayashi T, Kimura K, Azuma T: A theoretical approach to the volume pulse wave. AM HEART J 86:96, 1973.

8. Mendlowitz M: The digital blood flow, arterial pressure, and vascular resistance in arterial hypertension and in coronary thrombosis. J Clin Invest 21:539, 1942.

9. Caliva FS, Napodano RJ, Stafford RM, Loftus W, Lyons RH: Digital hemodynamics in the normotensive and hypertensive states. I. Digital mean arterial and venous pressures, blood flow, and vascular resistance. Circulation 28:415, 1963.

10. Conway J: A vascular abnormality in hypertension: A study of blood flow in the forearm. Circulation 27:520, 1963.

11. Folkow B, Grimby G, Thulesius O: Adaptive structural changes in the vascular walls in hypertension and their relation to the control of peripheral resistance. Acta Physiol Scand 255:272, 1959

12. Sivertsson R, Sannerstedt R, Lundgren Y: Evidence for peripheral vascular involvement in mild elevation of blood pressure in man. Clin Sci Molec Med 51:65s, 1976.

13. 'Takeshita A, Mark AL: Decreased vasodilator capacity of forearm resistance vessels in borderline hypertension. Hypertension 2:610, 1980.

14. Caliva FS, Napodano RJ, Lyons RH: Digital hemodynamics in the normotensive and hypertensive states. II. Venomotor tone. Circulation 28:421, 1963.

15. Takeshita A, Mark AL: Decreased venous distensibility in borderline hypertension. Hyptertension 1:202, 1979.

16. Nakayama R, Azuma T: Noninvasive measurements of digital arterial pressure and compliance in man. Am J Physiol 233:H168, 1977.

17. Gribbin B, Pickering TG, Sleight P: Arterial wall distensibility in hypertension (Abstr). Q J Med 41-42:531, 1972-73.

18. Peacock JH: Vasodilation in the human hand: Observations on primary Raynaud's disease and acrocyanosis of the upper extremities. Clin Sci 17:575, 1957.

19. Sivertsson R: The hemodynamic importance of structural vascular changes in essential hypertension. Acta Physiol Scand 343(Suppl):6, 1970. 